\title{
Model for Rheological Behavior of Crude Oil and Alkali-Surfactant- Polymer Emulsion
}

\author{
Renyi Cao ${ }^{*}, 1$ Linsong Cheng ${ }^{1}$ and Y. Zee $\mathrm{Ma}^{2}$

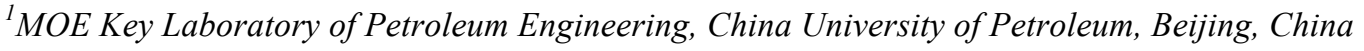 \\ ${ }^{2}$ Schlumberger, Denver, Colorado, USA
}

\begin{abstract}
Characterization of rheological behavior of alkali-surfactant-polymer (ASP) solution and oil emulsion is difficult, due to the complex chemical components and various physiochemical reactions with oil during chemical flooding. Through rheological experiments of ASP and crude oil emulsion, this paper presents the studies on influencing factors of rheological behavior, including interfacial tension, polymer and water cut, and discusses the stability mechanism of ASP and crude oil emulsion. The relationships among viscosity, interfacial tension, water cut and sheer rate were built through fitting the experimental data. The model and calculation can be used to more accurately simulate the ASP flooding in oil reservoirs.
\end{abstract}

Keywords: Emulsion, chemical flooding, rheological behavior, viscosity model.

\section{INTRODUCTION}

Alkali-surfactant-polymer (ASP) solution flooding has been used in oil reservoir developments since late 1980 s, and oil recovery can be greatly enhanced because of the synergistic effect of three chemical flooding [1,2]. One important mechanism of ASP flooding is that the in-situformed soaps resulted by alkali reacting with naturally occurring organic acid in crude oil, interact synergistically with added surfactant, which produces ultralow interfacial tension (IFT), increases the capillary number [3] and enhances microscopic displacing efficiency. Besides, the polymer could increase viscosity of solution to improve the mobility ratio, and also increase microscopic sweeping efficiency [2]. The ultralow IFT results in oil and water flowing through porous media in the form of emulsion [4]. Emulsions are playing a more and more important role in oil recovery as they are found to occur in most enhanced oil recovery processes and are involved in certain modes of crude oil transportation [5]. Furthermore, they can also be used in secondary recovery as blocking agents to improve water flooding performance in layered reservoirs or under bottom-water conditions [6].

Rheological behavior is impacted by multicomponents of aqueous phase, concentration of disperse phase and size of emulsion droplet [7]. Rheological behavior of ASP-oil emulsion is more complex due to chemical components and productions from chemical action of ASP-oil. Alvarado and Marsden [8] studied the flow of oil-in-water macroemulsions through both porous media and capillary, in which rheological behavior of macro emulsions with oil

*Address correspondence to this author at the MOE Key Laboratory of Petroleum Engineering, China University of Petroleum, Beijing, China; Tel:+8610 8973 3218; Fax:+8610 8973 3628;

E-mail: caorenyi@gmail.com concentrations ranging from $10 \%$ to $70 \%$ was obtained using capillary tube data; it was found that emulsions with oil concentrations less than $50 \%$ behaved like Newtonian fluids, while those with concentration greater than $50 \%$ behaved like pseudo plastic fluids. Coombe, Oballa and Buchanan [9] used a generalized compositional simulator to analyze the impact of non-Newtonian flow characteristics of polymers and emulsions at three length/time scales. In their study, the shear rate dependence of in situ emulsion generation suggested different modeling approaches at the core and field scales, with core scale rate processes replaced by pseudo-equilibrium $\mathrm{K}$ values at the field scale. Clark [10] studied the relationship between emulsion's rheological behavior and droplet size, and found that the viscosity of emulsion decreased with increasing droplet size. Khambharatana [5] investigated emulsion theologies and droplet captures for both caustic and surfactant emulsions flowing through Berea sandstone and Ottawa sand packs. His results showed that the change in emulsion rheology in a porous medium had an overall trend similar to that in a viscometer for the shear rates of interest; rheological behavior was found to be very different for the emulsion with different chemicals.

Although a number of studies have shown that the emulsion has the classic non-Newtonian flow characteristics, few studies have been carried out in the area of rheological behavior of emulsion during the ASP displacement process. Moreover, there is still a lack of a viscosity model, which could describe the emulsion rheology under influence of chemicals and be directly used in a flow simulator. Therefore, it is important to study the emulsion's flow behavior under the influence of polymer, surfactant and alkali simultaneously, which is the main subject of the present paper. 


\section{FLUIDS AND MEASUREMENT}

\section{ASP Solution and Oil}

The salinity of brine is $918 \mathrm{mg} / \mathrm{L}$ and the composition of ions is shown in Table 1. The ASP solution is the compound of alkali, surfactant, polymer and brine. In all tests the alkali is $\mathrm{NaOH}$, the surfactant is ORS-1 (petroleum sulfonate) and the polymer is HPAM (partially hydrolyzed polyacrylamide) with molecular weight 30 million. Oil is degassed crude oil.

Table 1. The contents of ions for brine.

\begin{tabular}{|c|c|c|c|c|c|c|c|}
\hline Ions & $\mathbf{N a}^{+}$ & $\mathbf{K}^{+}$ & $\mathbf{C a}^{2+}$ & $\mathbf{M g}^{2+}$ & $\mathbf{C l}^{-}$ & $\mathbf{S O}_{4}{ }^{2-}$ & $\mathbf{H C O}_{3}{ }^{-}$ \\
\hline \hline Contents (mg/L) & 36.8 & 20 & 131 & 12.7 & 78.7 & 34.1 & 54 \\
\hline
\end{tabular}

\section{Measurement}

We used the MCR301 rheometer to determine the viscosity of emulsion. All tests were conduct at $25^{\circ} \mathrm{C}$ and one ambient pressure.

\section{INFLUENCE FACTORS OF EMULSION VISCOSITY}

\section{Impact of Polymer}

Oil - water interface could be changed by ASP solution, which is different from the purity oil-water emulsion in emulsification mechanism, emulsion viscosity and emulsion stability. Although it is known that the surfactant or in-situformed soaps resulted by alkali reacting with oil could decrease interface tension, there is not a definite conclusion regarding how polymer impacts emulsification mechanism and emulsion stability.

Most oil fields use HPAM (Water-soluble hydrolyzed polyacrylamide) as thickener in chemical flooding - a type of macromolecule water-solubility polymer. As the polymer chains could twine with each others, the polymer solution shows the property of viscoelasticity. Since interface intension and strength are two of the most important factors for emulsion's stability, we could analyze the impact of HPAM on the interface intension and strength and the impact of polymer on emulsification.

The interface tension is between $12-18 \mathrm{mN} / \mathrm{m}$ for polymer solution (HPAM, molecular weight 1500) and oil after 30 minutes of mixing in rotary agitator under the ratio of water/oil equal to $1.0\left(f_{\mathrm{w}}=50 \%\right)$ with polymer concentration from 0 to $1600 \mathrm{mg} / \mathrm{L}$, and it's much larger than the value of ultra-low interfacial tension $\left(10^{-3} \mathrm{mN} / \mathrm{m}\right)$, so that water or oil easily separates from "emulsion" and the emulsion can't maintain steady emulsification state.

The stabilization mechanism is different for polymer in $\mathrm{W} / \mathrm{O}$ emulsion and $\mathrm{O} / \mathrm{W}$ emulsion. The interface film could be described as in Fig. (1) for $\mathrm{W} / \mathrm{O}$ and $\mathrm{O} / \mathrm{W}$ emulsion. For the $\mathrm{O} / \mathrm{W}$ emulsion, polymer solution is a continuous phase and the polymer molecules could form a sticky protective layer around the oil droplets, which could blocked the oil droplets to combine with each others. Furthermore, the longer chains of polymer molecules could induce strong space resistance between the droplets and keep the structure of adsorbent interface layer tightening, so that the polymer can efficiently stabilize the $\mathrm{O} / \mathrm{W}$ emulsion [11]. On the other hand, for the $\mathrm{W} / \mathrm{O}$ emulsion, polymer solution is a disperse phase that is constrained in droplets; the water droplets can easily combined by overcoming the weak resistance induced from the lipophilic group of surfactant in oil phase, and thus polymer solution can't affect the W/O emulsion's stability.

Another important factor of polymer solution stabilizing $\mathrm{O} / \mathrm{W}$ emulsion is that the continuous phase polymer solution has strong shearing layer viscosity. The shearing viscosity of interface increases with increase of concentration of polymer. The impact of polymer on the shearing viscosity of interface is embodied on the adsorption of polymer on the interface. When the concentration of polymer is low, the interaction of polymer molecules is weak. Thus, the interface film could be considered as the gaseous film and the shearing viscosity of interface is very low under this condition. Once the concentration of polymer increases to a certain value, the molecules of polymer will rapidly interact on the interface layer and be limited in freedom motion, which means that the monomolecular film on the interface rapidly transits to the liquid film and the shearing viscosity of interface rapidly increases at the same time. Moreover, the external phase in $\mathrm{O} / \mathrm{W}$ emulsion polymer solution efficiently increases the viscosity of water phase, and it decreases the probability of oil droplet's collision. Therefore, with the high viscosity of external phase and high intensity of water film, the $\mathrm{O} / \mathrm{W}$ emulsion tends to be stable as a result of polymer solution.

However, for $\mathrm{W} / \mathrm{O}$ emulsion, the intensity of oil film depends on the interaction force from oleophilic groups of surfactant molecular. The distribution coefficient of polymer

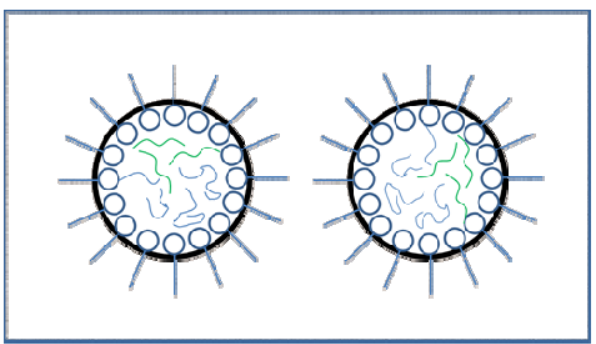

W/O emulsion

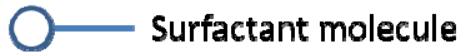

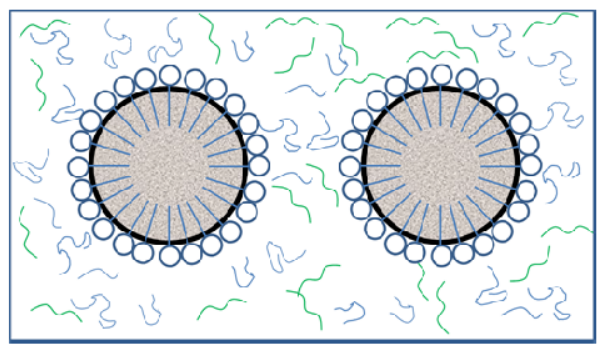

$\mathrm{O} / \mathrm{W}$ emulsion

Polymer molecule

Fig. (1). Mechanism of polymer solution stabilizing $\mathrm{W} / \mathrm{O}$ and $\mathrm{O} / \mathrm{W}$ emulsion. 
in oil phase is very small, and the impact of polymer on intensity of oil film is very poor to $\mathrm{W} / \mathrm{O}$ emulsion.

\section{Impact of Interface Tension}

Alkali could react with the acid components of crude oil into some active molecules like surfactant, so that the active molecules from reactant and the original surfactant from ASP can largely decrease the interfacial tension (IFT). As a result, the rheological behavior of emulsion is changed. Fig. (6) shows the relationship between the viscosity of emulsion and concentration of surfactant. Through measuring the IFT of ASP with different concentrations of surfactant, we can establish the relationship between the shearing viscosity of emulsion and IFT (Fig. 2), which shows that viscosity decreases with reduction of IFT. The surfactant could enhance the interface strength and stability of emulsion droplet, and it could also increase its quantity and decrease its size. Therefore, the probability of emulsion droplet collision will be increased with the increasing surfactant and decreasing IFT.

The concentration of active molecule and surfactant could be characterized through the IFT of ASP and crude oil, and the result is equivalent to the impact of alkali and surfactant. From Fig. (2), we could find that both the $\mathrm{O} / \mathrm{W}$ and $\mathrm{W} / \mathrm{O}$ emulsion fit the same relationship between the IFT of surfactant and viscosity of emulsion, and the viscosity of emulsion increases as the IFT decreases. The relation could be fitted by

$$
\mu=A \lg (\sigma)+B
$$

where $\mu$ is the viscosity of continuous phase, mPa.s; $\sigma$ is the IFT of emulsion, $\mathrm{N} / \mathrm{m}$; and $\mathrm{A}$ and $\mathrm{B}$ are parameters.

\section{Impact of Water Cut}

For ASP-oil emulsion, water cut directly impacts the phase inversion. The concentration of dispersed phase increases when water cut is close to the phase inversion point (water cut at phase inversion), which increases the possibility of collision between dispersed phases. When the concentration of dispersed phase reaches a certain value, the intensity of interfacial film of emulsion droplets decreases. Therefore, the emulsified phase cannot maintain an independent dispersed phase, the phase inversion of emulsion happens, the dispersed phase turns into a continuous phase and the continuous phase turns into a dispersed phase.

As for rheological property, as apparent viscosity changes significantly after phase inversion of emulsion, the phase inversion point can be determined by measuring the apparent viscosity. Fig. (3) represents the apparent viscosity of emulsion before and after phase inversion by rheometer. When the concentration of dispersed phase is low, the distance between dispersed phase droplets is long, interaction force is small, and dispersed phase has limited impact on the continuous phase. When the concentration of dispersed phase increases, the distance between emulsion droplets decreases, interaction force strengthens, and collision and slippage between droplets take place, leading to a rapid increase of apparent viscosity. This shows the regularity of apparent viscosity change before and after phase inversion point.

Viscosity is a fundamental parameter describing rheological property of emulsion. For dilute solution of emulsion, the property is similar to Newtonian fluid. The Einstein formula is known to be useful to describe dilute solution viscosity $[12,13]$.

For ASP flooding in oil reservoir, due to the interactions between ASP chemical agents and crude oil, the ASP-oil emulsion is more complicated than dilute dispersed system as it is a non-Newtonian fluid system. In order to make the emulsion model more applicable in a larger concentration range of dispersed phase, description model and parameters should be determined by fitting the experiment data.

In matching the rheology experimental data, Gauss function can be used to describe viscosity of emulsion. By assuming that emulsion can be completely emulsified, the Gauss function could be expressed as [14]:

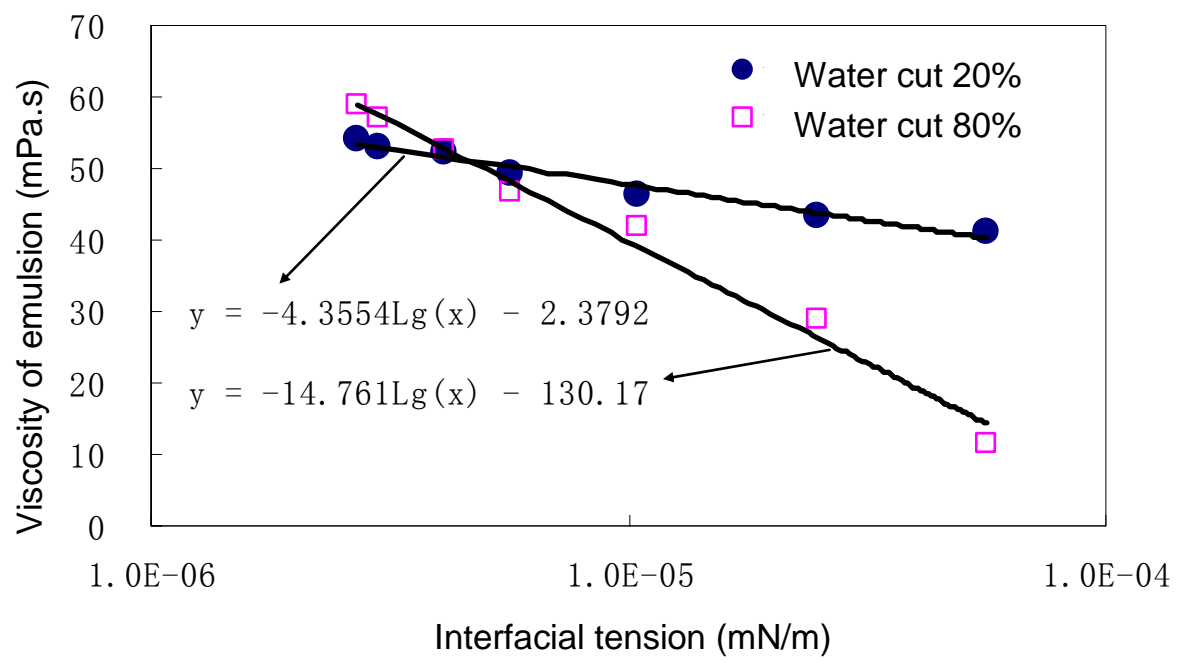

Fig. (2). Relationship between IFT and the shearing viscosity of emulsion. Notice that the abscissa is logarithmic. The polymer concentration is $0.5 \%$, and the concentration of ASP is $0.5 \%$ HPAM $+0.3 \% \mathrm{NaOH}+0.1 \% \sim 0.5 \%$ ORS- 41 . The viscosity is tested under shear rate $100 \mathrm{~s}^{-1}$. 


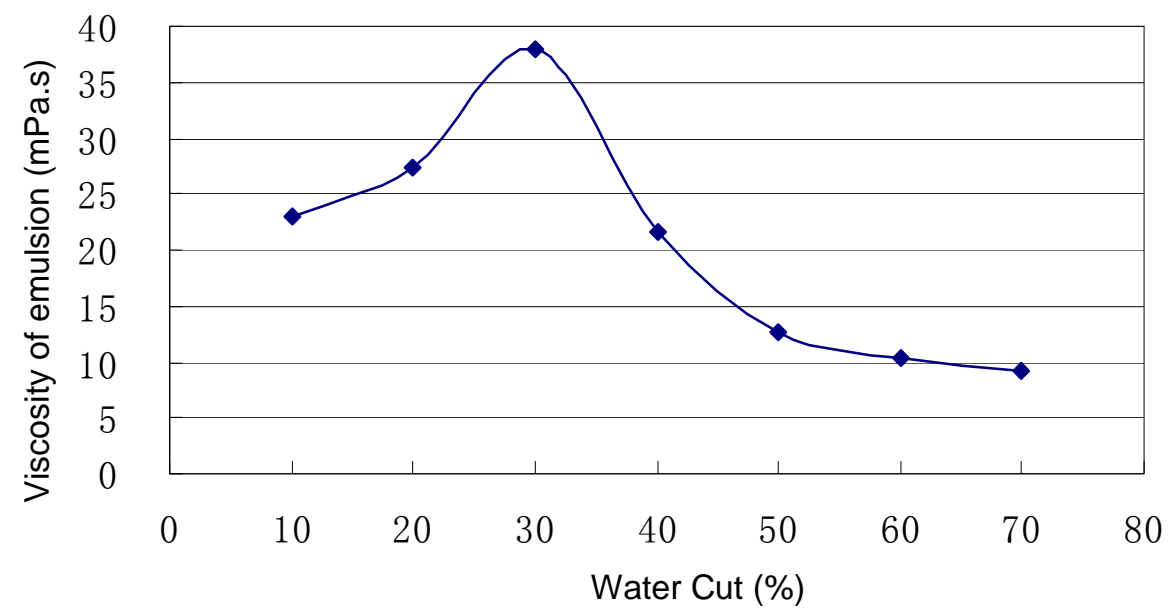

Fig. (3). ASP $(0.3 \% \mathrm{NaOH}+0.3 \%$ ORS- $41+0.5 \%$ HPAM) -oil emulsion apparent viscosity change before and after phase inversion point.

$\mu\left(f_{w}\right)=a e^{-\left(f_{w}-f_{w c}\right)^{2} / c^{2}}$

where $f_{w}$ is water cut of emulsion; $f_{w c}$ is the water cut at phase inversion point; $a, c$ are fitting parameters from experiment data.

When water cut is $0 \%$ or $100 \%$, the viscosity of ASP-oil emulsion is the viscosity of oil or ASP solution, respectively. The equation that accounts for the ASP-oil emulsion [14] and the boundary condition is expressed:

$\mu=\mu_{0}+\left(\mu_{A S P}-\mu_{0}\right) f_{w}{ }^{s}+\frac{A_{r}}{W \sqrt{\pi / 2}} \exp \left[-2 \frac{\left(f_{w}-f_{w c}\right)^{2}}{W^{2}}\right]$

where $A_{\mathrm{r}}$ is the integral of viscosity of different water cut emulsion, mPa.s; $W, s$ are fitting parameters related to chemicals; $\mu_{A S P}$ is the viscosity of ASP flooding.

\section{Impact of Sheer Rate}

Fig. (4) presents the rheological curves of $\mathrm{W} / \mathrm{O}$ and $\mathrm{O} / \mathrm{W}$ emulsion formed by ASP solution and crude oil; the ASP solution is $0.3 \% \quad \mathrm{NaOH}+0.3 \%$ ORS- $41+1.2 \%$ HPAM. Through emulsion type testing, water cut of the W/O emulsion is $10 \%$, and water cut of $\mathrm{O} / \mathrm{W}$ emulsion is $80 \%$. The fittied curves show that both the rheological relationships of $\mathrm{W} / \mathrm{O}$ and $\mathrm{O} / \mathrm{W}$ emulsion approximately follow a power-law model, such as

$\mu=H \dot{\gamma}^{n-1}$

where, $H$ is shearing viscosity at $1.0 \mathrm{~s}^{-1}$, mPa.s.

For the $\mathrm{O} / \mathrm{W}$ emulsion, because the continuous phase is ASP solution, so the rheological behavior of $\mathrm{O} / \mathrm{W}$ emulsion is more affected by polymer solution, and the pseudo plasticity of the $\mathrm{W} / \mathrm{O}$ emulsion is weaker than the $\mathrm{O} / \mathrm{W}$ emulsion.

\section{MODEL AND CALCULATING PROCESS OF EMULSION VISCOSITY IN ASP FLOODING}

In ASP flooding, it is important to know the viscosity of fluid during flowing in porous media, but the viscosity of the fluid cannot be measured under the condition of oil reservoir. Hence, it is necessary to build a model that calculates the viscosity according to the amount of water, oil and chemical

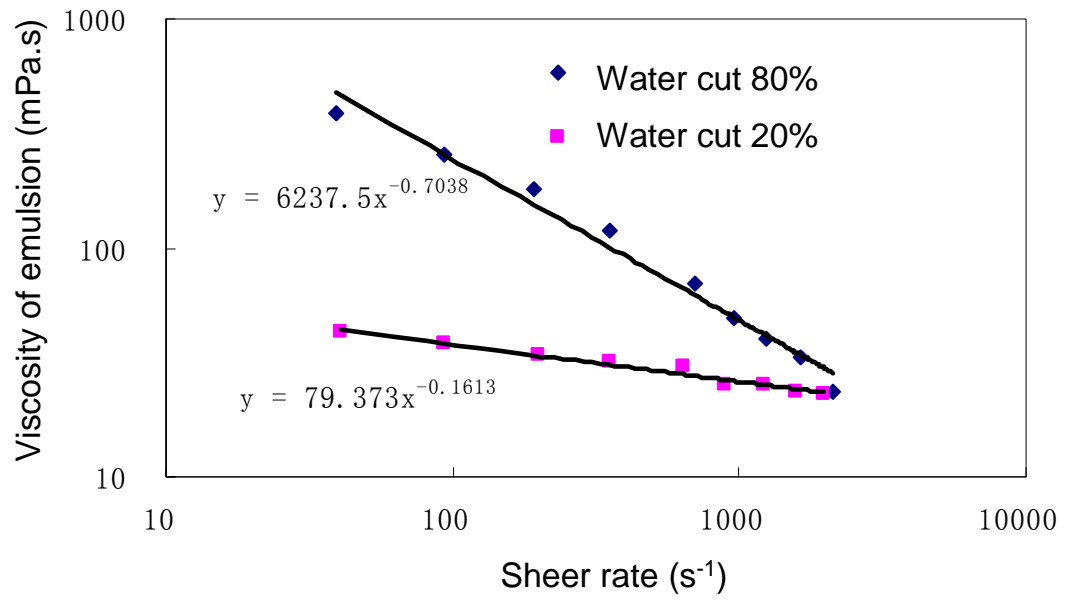

Fig. (4). Rheological curves of emulsion of ASP solution and crude oil with water cut of $20 \%$ and $80 \%$, respectively. The ASP solution is $0.3 \% \mathrm{NaOH}+0.3 \%$ ORS- $41+1.2 \%$ HPAM. Based on emulsion type test, emulsion of water cut at $10 \%$ is W/O emulsion, and emulsion of water cut $80 \%$ is $\mathrm{O} / \mathrm{W}$ emulsion. 
agents, sheer rate, etc. The model includes the following steps:

1. Measure the viscosity of ASP solution at a certain sheer rate;

2. Determine the phase inversion point according to the viscosity and interfacial tension of ASP system and crude oil;

3. Estimate the ASP-oil emulsion type based on the phase inversion point, determine the emulsification, and divide the compound system into incomplete emulsion phase, and emulsion phase;

4. If emulsion is $\mathrm{W} / \mathrm{O}$ type, there exists $\mathrm{W} / \mathrm{O}$ emulsion and water phase (incomplete emulsion) in reservoir. Thus, water phase viscosity model matches the viscoelastic polymer emulsion model. Otherwise, emulsion is $\mathrm{O} / \mathrm{W}$ type, there exist $\mathrm{O} / \mathrm{W}$ emulsion and emulsified oil phase;

5. In an oil reservoir, we can build 3 equations of motion based on the viscosity model to simulate every phase's flow condition for calculating the flow of ASP flooding in porous media. The viscosity model of oil phase could use the conventional Newton rheology model, the viscosity model of water phase (ASP solution) could use the viscoelastic polymer emulsion model, and the viscosity of ASP/oil emulsion calculation could use the modified model (Gauss function Eq.3 and Power-Law model in Eq.4). The latter model is fitted by water cut and sheer rate to describe $\mathrm{W} / \mathrm{O}$ and $\mathrm{O} / \mathrm{W}$ emulsion viscosity (Fig. 5). For the ASP or polymer flooding in reservoir, we could also use the viscoelsatic model (Eq. 5) of polymer solution in porous media to approximate the ASP flooding [15].

$$
\mu_{\text {polymer }}=\left(1+\frac{\frac{12 n}{3 n+1} \alpha \dot{\gamma} \theta_{f}\left(1-\frac{1}{\lambda_{1}^{6}}\right)-\frac{\left(B^{4}-1\right)^{1 / 2}}{(1+\beta) \alpha^{1}}\left(1-\frac{1}{\lambda_{3}^{3}}\right)}{\frac{1}{\alpha}\left(1-\frac{1}{\lambda_{1}^{3}}\right)+6 \xi+\frac{1}{\alpha^{\prime}} \cdot\left(1-\frac{1}{\lambda_{3}^{3}}\right)}\right) H \dot{\gamma}^{n-1}
$$

We used the new model to calculate the viscosity of emulsion. The Fig. $(\mathbf{6 a}, \mathbf{b})$ show the verification of oil and water emulsion (the experimental data is from the reference 14). The Fig. (6c, d) show the verification of ASP solution and oil emulsion (ASP solution 0.5\% HPAM +0.3\% ORS$41+0.3 \% \mathrm{NaOH}$, the oil viscosity are $20 \mathrm{mPa} . \mathrm{s}$ in Fig. (6c) and $15 \mathrm{mPa} . \mathrm{s}$ in Fig. (6d). It is shown that this model can predict the relationship between water cut and viscosity accurately.

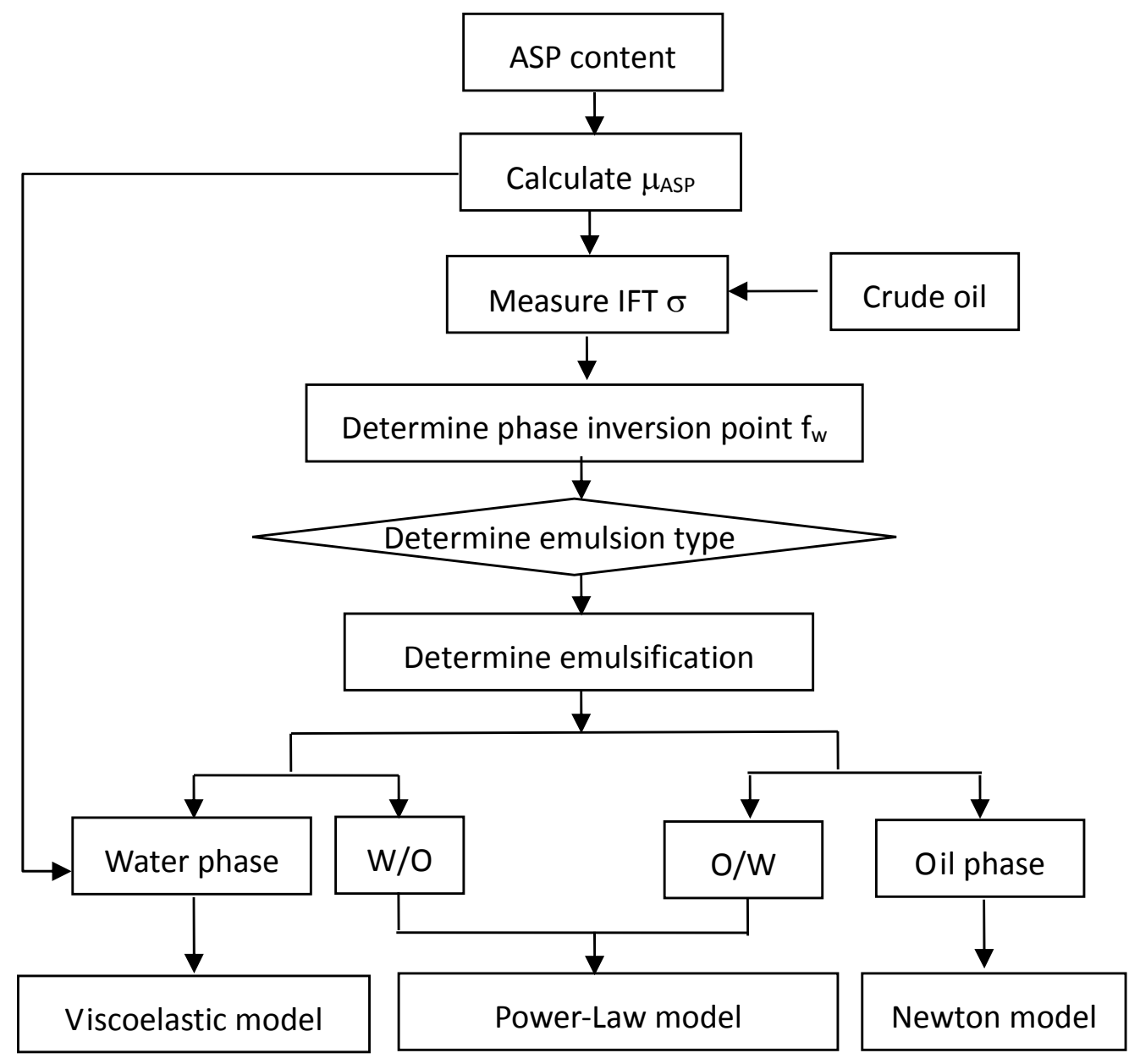

Fig. (5). Calculation steps in emulsion viscosity of ASP system model. 


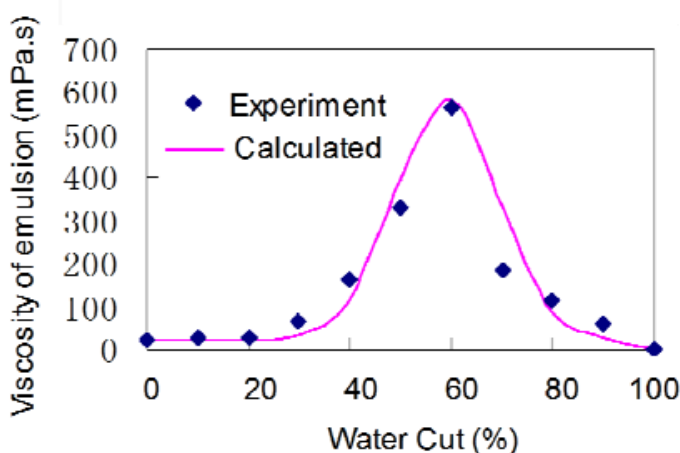

(a)

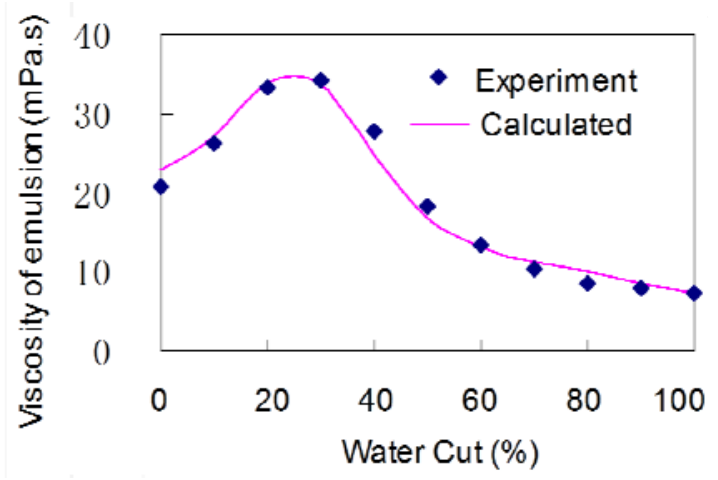

(c)

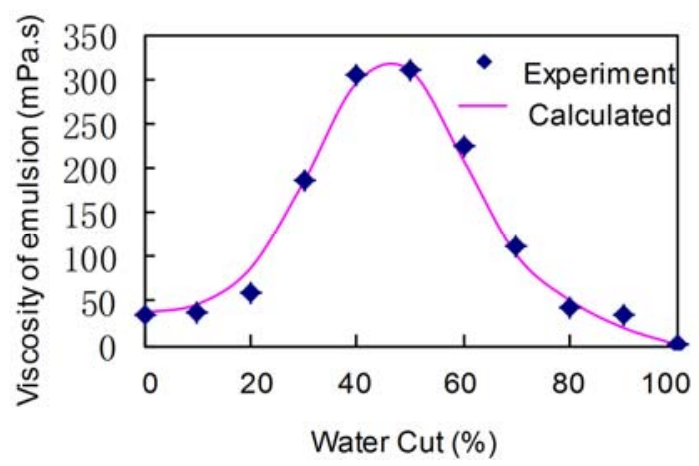

(b)

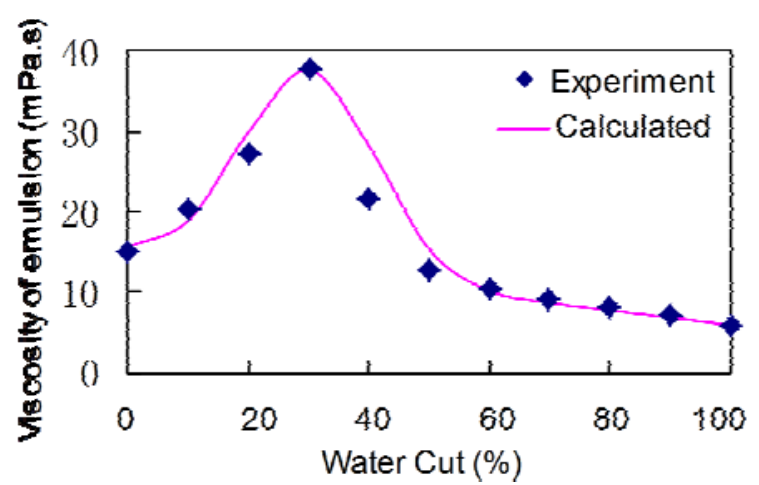

(d)

Fig. (6). Comparison of emulsion prediction model and experiment data.

\section{CONCLUSION}

We draw the following conclusions from our study.

Surfactant concentration is a main factor of emulsion stability and rheology. With lower high concentration of surfactant and low interfacial tension, the ASP solution and oil emulsion are stable and the viscosity of emulsion is high. The impact of interfacial tension on performance is much larger in $\mathrm{W} / \mathrm{O}$ emulsion than $\mathrm{O} / \mathrm{W}$ emulsion. There is a good logarithm relationship between the viscosity and interfacial tension of emulsion.

(2) For the $\mathrm{O} / \mathrm{W}$ emulsion formed by ASP solution and oil, polymer is dissolved in water phase and decreases the collision probability of emulsion drops, and it could increase the stability of $\mathrm{O} / \mathrm{W}$ emulsion. For $\mathrm{W} / \mathrm{O}$ emulsion, the influence of polymer is limited. Polymer solution and oil alone cannot form into a more stable emulsion. The rheology of $\mathrm{O} / \mathrm{W}$ emulsion is similar to polymer solution.

(3) As the water cut increases, the $\mathrm{W} / \mathrm{O}$ emulsion gradually inverts to $\mathrm{O} / \mathrm{W}$ emulsion, and its viscosity increases initially and then gradually decreases after reaching the phase inversion point. The relationship between viscosity and water cut of emulsion could be nicely fitted with a modified Gauss function.
(4) For simulation of ASP flooding in oil reservoir, it is possible to build different flow models of water phase (ASP solution), oil phase and emulsion phase. Viscosity model of oil phase can use the Newton model, water phase can use a viscoelastic model in porous media, and emulsion can use a Power-Law model.

\section{CONFLICT OF INTEREST}

The authors confirm that this article content has no conflict of interest.

\section{ACKNOWLEDGEMENTS}

This work was financially supported by the National Natural Science Foundation of China (No. 51304220), Beijing Natural Science foundation (No.3144033) and Specialized Research Fund for the Doctoral Program of Higher Education of China (No.20130007120014).

\section{REFERENCES}

[1] Wang, D.; Cheng, J.; Li, Q.; Jiang, Y.; Sun, Y.; He, Y. Experience of ior practices from large-scale implementation in layered sandstones. In: SPE Asia Pacific Oil and Gas Conference and Exhibition, Brisbane, Australia, SPE 64287-MS, 2000.

[2] Wang, D.; Cheng, J.; Yang, Q. Viscous-elastic polymer can increase microscale displacement efficiency in cores. In: SPE 
Annual Technical Conference and Exhibition held in Dallas, Texas, SPE 63227, 2000.

[3] Martin, F. D. Enhanced recovery of a ' $\mathrm{j}$ ' sand crude oil with a combination of surfactant and alkaline chemicals. In: 60th Annual Tech. Conf. and Exhibition of the SPE, Las Vegas, NV, SPE 14293, 1995.

[4] Tong Z.S.; Yang C.Z.; Wua G.Q. A study of microscopic flooding mechanism of surfactant/alkali/polymer. In: Improved Oil Recovery Symposium Held in Tulsa, Oklahoma, SPE 39662, 1998.

[5] Khambharatana, F.; Thomas S.; Ali, S.M.F. Macroemulsion rheology and drop capture mechanism during flow in porous media. In: SPE International Oil and Gas Conference and Exhibition in Beijing, China, SPE 48910, 1998.

[6] Ezeddin, S. Mobility control by polymers under bottom-water conditions, experimental approach. In: SPE Asia Pacific Oil and Gas Conference and Exhibition, Brisbane, Australia, SPE 64506, 2000.

[7] Uzoigwe, A.C.; Marsden Jr. S.S. Emulsion rheology and flow through unconsolidated synthetic porous media. In: AIME 45th Annual Fall Meeting, Houston, SPE 3004, 1970.

[8] Alvarado, D. A.; Marsden, Jr. S.S. Flow of oil-in-water emulsions through tubes and porous media. Soc. Petrol. Eng. J., 1979, 19(6), 369-377.
[9] Coombe, D.A.; Oballa, V.; Buchanan, W.L. Scaling up the nonNewtonian flow characteristics of polymers, foams, and emulsions. In: SPE Symposium on Reservoir Simulation, New Orleans, Louisiana, SPE 25237, 1993.

[10] Clark Jr. L.C.; Shaw, R.F. Stable emulsions of highly fluorinated organic compound. European Patent 0231091, March 31, 1993.

[11] Kang, W.L.; Yue, X.A. Hu, J.B., The stability of polymer effect on emulsion and liquid membrane, Acta Petrol. Sin., 1997,18(4):122125.

[12] Masalova, I.; Malkin, A. Y.; Slatter, P.; Wilson, K. The rheological characterization and pipeline flow of high concentration water-inoil emulsions. J. Non-Newton. Fluid Mech., 2003,112(2),101-114.

[13] Urdahl, O.; Fredheim, A.O.; Løken, K. P. Viscosity measurements of water-in-crude-oil emulsions under flowing conditions: A theoretical and practical approach. Colloid. Surf. A, 1997,123, 623634.

[14] Zhang, F.; Qin, J.S.; Zhang, X. A study on rheology property of emulsion of crude oil. Xinjiang Petrol. Geol., 2006, 27(5), 575-578.

[15] Cheng, L.S.; Cao, R.Y. Constitutive model of viscous-elastic polymer solution in porous media. Petrol. Sci. Technol., 2010, $28(11), 1170-1177$.

(C) Cao et al.; Licensee Bentham Open.

This is an open access article licensed under the terms of the Creative Commons Attribution Non-Commercial License (http://creativecommons.org/licenses/by-nc/3.0/) which permits unrestricted, non-commercial use, distribution and reproduction in any medium, provided the work is properly cited. 